\title{
Analysis of functional indices indicates multiple organ function damage in patients with severe Coronavirus Disease 2019 (COVID-19) pneumonia
}

\section{Shiyan Feng}

Department of Infectious Diseases, Shenzhen Third People's Hospital, Second Hospital Affiliated to Southern University of science and Technology , Shenzhen, 518000, Guangdong Province, China

\section{Fengxin Wang}

Department of Infectious Diseases, Shenzhen Third People's Hospital, Second Hospital Affiliated to Southern University of science and Technology , Shenzhen, 518000, Guangdong Province, China

\section{Zhao Cai}

School of Medicine, Southern University of Science and Technology, Shenzhen, 518055, China

\section{Weibo Wu}

Department of Infectious Diseases, Shenzhen Third People's Hospital, Second Hospital Affiliated to Southern University of science and Technology , Shenzhen, 518000, Guangdong Province, China

\section{Yinfeng Li}

Department of Infectious Diseases, Shenzhen Third People's Hospital, Second Hospital Affiliated to Southern University of science and Technology , Shenzhen, 518000, Guangdong Province, China

\section{Li Chen}

Department of Infectious Diseases, Shenzhen Third People's Hospital, Second Hospital Affiliated to Southern University of science and Technology , Shenzhen, 518000, Guangdong Province, China

\section{Chuming Chen}

Department of Infectious Diseases, Shenzhen Third People's Hospital, Second Hospital Affiliated to Southern University of science and Technology , Shenzhen, 518000, Guangdong Province, China

\section{Mengli Cao}

Department of Infectious Diseases, Shenzhen Third People's Hospital, Second Hospital Affiliated to Southern University of science and Technology , Shenzhen, 518000, Guangdong Province, China

\section{Ling Peng}

Department of Infectious Diseases, Shenzhen Third People's Hospital, Second Hospital Affiliated to Southern University of science and Technology , Shenzhen, 518000, Guangdong Province, China

Xiao Jiang

Department of Infectious Diseases, Shenzhen Third People's Hospital, Second Hospital Affiliated to Southern University of science and Technology , Shenzhen, 518000, Guangdong Province, China

\section{Peiyan Zhang}


Department of Infectious Diseases, Shenzhen Third People's Hospital, Second Hospital Affiliated to Southern University of science and Technology , Shenzhen, 518000, Guangdong Province, China

\section{Jianming Li}

Department of Infectious Diseases, Shenzhen Third People's Hospital, Second Hospital Affiliated to Southern University of science and Technology , Shenzhen, 518000, Guangdong Province, China

\section{Liuqing Yang}

Department of Infectious Diseases, Shenzhen Third People's Hospital, Second Hospital Affiliated to Southern University of science and Technology , Shenzhen, 518000, Guangdong Province, China

\section{Yingxia Liu}

Department of Infectious Diseases, Shenzhen Third People's Hospital, Second Hospital Affiliated to Southern University of science and Technology , Shenzhen, 518000, Guangdong Province, China

\section{Lei Liu}

Department of Infectious Diseases, Shenzhen Third People's Hospital, Second Hospital Affiliated to Southern University of science and Technology , Shenzhen, 518000, Guangdong Province, China

\section{Liang Yang ( $\nabla$ yangl@sustech.edu.cn )}

School of Medicine, Southern University of Science and Technology, Shenzhen, 518055, China

\section{Fuxiang Wang ( $\nabla$ wangfuxiang999@163.com )}

Department of Infectious Diseases, Shenzhen Third People's Hospital, Second Hospital Affiliated to Southern University of science and Technology , Shenzhen, 518000, Guangdong Province, China

\section{Research Article}

Keywords: Severe cases, Coronavirus Disease 2019 (COVID-19) pneumonia, Organ function index

Posted Date: June 4th, 2020

DOl: https://doi.org/10.21203/rs.3.rs-32482/v1

License: (c) (1) This work is licensed under a Creative Commons Attribution 4.0 International License. Read Full License 


\section{Abstract}

Background: This study aims to analyze the changes and significance of organ function indices in patients with severe Coronavirus Disease 2019 (COVID-19) pneumonia for prediction of major organ damages and guiding treatment schemes.

Methods: 63 patients with severe COVID-19 pneumonia were selected as the severe group and 73 patients with mild syndromes were selected as the mild group. SAS9.4 software was used for statistical analysis of the data.

Results: Levels of ALT, AST, cTnl, Cr, PT, APTT and D-DIC of the severe group were significantly higher while PLT was lower than those of the mild group. The data of all quantitative variables were converted into categorical variables. Significantly higher levels of AST, ALB, D-DIC and higher proportion of bilateral lung involvement were observed from the severe group comparing to those in the mild group, while the difference in the other indices between the two groups was insignificant in statistical perspective.

Discussion: There are significant differences in the levels of multiple organ function indices between the severe group and the mild group of patients with COVID-19 pneumonia infection. Through examining the relevant indices, conditions of patients' multiple organ function damage could be predicted and used as guidance of treatment.

\section{Introduction}

Since the start of the outbreak of Coronavirus Disease 2019 (COVID-19) infection from Dec 2019 in Wuhan, China, it now becomes a worldwide pandemic and affects almost everyone in the world. According to the latest statistics of National Health Commission of the People's Republic of China, there were 84522 confirmed cases and 4645 deaths being reported in China on 24 May 2020. In total, there were more than 5.1 millions confirmed cases and 333401 deaths reported from 216 countries, areas or territories in the worldwide as released by World Health Organization on 24 May 2020. (www.who.int)

COVID-19 is highly infectious with high speed of transmission and high mortality rate.[1] Its routes of transmission from person to person include aerosol, fecal-oral, ocular surface and secretions and etc.[13] It has been reported that mortality rate is higher in the aged patients and those with chronic underlying diseases such as diabetes and cardiovascular diseases. [4, 5] Typical symptoms of COVID-19 infection include fever, coughing, muscle ache, fatigue, chest pain and etc.[6] Various studies investigated the changes in the level of blood routine indices and sequential organ failure assessment scores to assess the infection progression in the patients.[7-9] Moreover, SARS-CoV-2 viral infection would damage various major organs and tissues including the liver, the kidney, the heart and the blood, and is able to develop to multiple fetal organ failures leading to the death of the patients. $[6,7,10,11]$ Deaths of COVID-19 infected kidney transplant recipients were also reported, showing the influence of this virus on major organ functions.[12] However, current treatment measures taken towards COVID-19 infection are still mostly supportive and unspecific. Alternative treatment measures have been tested. Improvements of 
the clinical conditions could be seen from critically ill patients after receiving antibody-containing covalescent plasma transfusion.[8] However, further thorough study is still needed on the effectiveness of this treatment measure. Therefore, it is spectacularly important to monitor the relevant indices of organ functions to predict the severity of the infection for patient protection and corresponding treatments. In this study, we analyzed multiple organ function indices of 136 COVID-19 pneumonia patients and compared the differences in the index levels between the severely ill patients and the patients with mild syndromes to understand the progress and the outcome of the COVID-19 infection for better disease control and more effective treatment.

\section{Materials And Methods}

\subsection{Patients}

From January 2020 to March 2020, among the COVID-19 pneumonia patients charged into The Third People's Hospital of Shenzhen (the designated medical institution for COVID-19 pneumonia treatment in Shenzhen), 63 severe COVID-19 pneumonia patients were selected as the severe group among which 39 patients are male and 24 patients are female, aged from 21 to 86 years old with average age of 61.3 years. 73 mild COVID-19 pneumonia patients were selected as the mild group among which 30 patients are male and 43 patients are female, aged from 1 year 8 months to 79 years old with average age of 40.5 years. Patients' complete details can be found from Table S1. The level of severity is classified according to the classification guidance provided by the fifth edition of Novel Coronavirus Pneumonia Diagnosis and Treatment Plan.

\subsection{Sample collection and tests}

This study is approved by the Ethics Committees from Shenzhen Third People's Hospital(2020-142). The index values of peripheral venous blood samples collected on admission from the two groups of patients were used for retrospective analysis. The biochemical indices and blood routine indices of the blood samples were examined using chemiluminescent method. Patients' lung involvement conditions and the results of colour echocardiography were also collected. Data and reference ranges are listed in Table S1.

\subsection{Statistical analysis}

SAS9.4 software was used for the statistical analysis of the indexes. Kolmogorov-Smirnov test was adopted to check the normality of the quantitative data. The data following normal distribution is expressed as mean \pm standard deviation (false) while the data not following normal distribution is expressed as median (interquartile range). Inter-group comparison of the normally distributed data was done using Student's $t$ test while the inter-group comparison of the non-normally distributed data was done using Wilcoxon rank-sum test. Inter-group comparison of the qualitative data was done using Chi- 
square test. Fisher's exact test was applied for those unfitted for Chi-square test. Significant statistical difference is indicated by $p<0.05$.

\section{Results}

\subsection{Patients epidemiological history and chronic diseases}

Based on the information collected, patients in the severe group have higher average age of 61.3 years and more chronic diseases. In the severe group, 44 patients had residential/contact history to Wuhan/Hubei epidemic areas while 4 patients had contact history with confirmed cases. 2 patients had neither been in Wuhan/Hubei or in contact with any confirmed case. 34 patients have at least one type of chronic diseases, including hypertension, diabetes, coronary heart disease, arrhythmia, COPD and hepatitis B. 13 of them have two or more underlying diseases. Six patients turned to critical state and three of them died. Two died cases were with either hypertension or COPD while the third case had no chronic disease history. The other three critical cases had chronic disease history of hypertension or diabetes, or both. Other patients were discharged upon recovery. The average course of disease was 4.9 days while average length of hospitalization was 29 days.

In the mild group, 53 patients had residential/contact history to Wuhan/Hubei epidemic areas. 13 patients had contact history with confirmed cases. 7 patients had no epidemiological history. 13 of the patients have at least one type of chronic diseases, including hypertension, diabetes, emphysema, tuberculosis, hyperlipemia, hepatitis B and cirrhosis at decompensation stage. 2 patients have two underlying chronic diseases. All of the patients in the mild group were discharged upon recovery. The average course of disease was 3.6 days while average length of hospitalization was 19 days. (Table S1)

\subsection{Inter-group comparison of the levels of multiple organ function indices}

From the results of biochemical test and blood routine tests, significant differences in the levels of multiple organ function indices were seen between the severe group and the mild group. Statistically, positive $t$ or $z$ value represents a higher mean/median value of the index level in the severe group comparing to the mild group, and vice versa. The higher the absolute t or $z$ value, the more different in the index level between the two groups and the lower the p-value. (Table 1)

Significantly lower oxygenation index was detected from the severe group comparing to the mild group. Levels of liver function indices, alanine aminotransferase (ALT) and aspartate aminotransferase(AST), are significantly higher, while level of albumin is lower in the severe group. Elevated concentrations of immune system function indices including C-reactive protein(CRP), procalcitonin(PCT), erythrocyte sedimentation rate (ESR), neutrophil count and interleukin-6 (IL-6) but lower lymphocyte count were also observed in the severe group. Longer plasma prothrombin time (PT) and activated partial 
prothrombin time (APTT), higher level of D-Dimer and lower platelet counts were detected from the severe group. Kidney function index, creatinine(Cr), and heart function index, troponin( $\mathrm{Tnl})$, were also increased in patients with severe syndromes. No difference was observed from other indices between the two groups in statistical perspective. (Table 1, details in Table S1) These results are possibly indicating altered functions of major organs and systems including the heart, the liver, the kidney, the immune system and the blood coagulation system as the severity of the infection increased.

Table 1: Comparis on of the levels of indices between the severe group and the mild group. Numbers in the bracket represents the range of the particular index detected in the group.

\begin{tabular}{|c|c|c|c|c|}
\hline \multicolumn{5}{|c|}{ 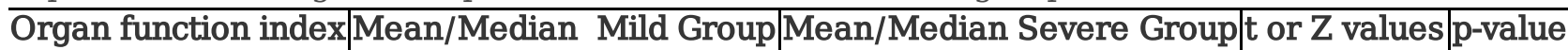 } \\
\hline \multicolumn{5}{|c|}{ Liver function indices } \\
\hline $\mathrm{ALT}(\mathrm{U} / \mathrm{L})$ & $20(14.15-27)$ & $26(18-35)$ & 2.323 & 0.02 \\
\hline $\mathrm{AST}(\mathrm{U} / \mathrm{L})$ & $27.75(22-35)$ & $33(24.2-45)$ & 2.38 & 0.017 \\
\hline TBIL(umol/L) & $9.2(7.7-13.6)$ & $10.5(7.8-13.6)$ & 0.333 & 0.739 \\
\hline $\mathrm{Alb}(\mathrm{g} / \mathrm{L})$ & $43.2(41.65-45.7)$ & $39.7(37.9-43)$ & -5.424 & $<0.001$ \\
\hline \multicolumn{5}{|c|}{ Kidney function index } \\
\hline $\mathrm{Cr}(\mathrm{umol} / \mathrm{L})$ & $59.35(50-75.2)$ & $68(55.5-95)$ & 2.695 & 0.007 \\
\hline \multicolumn{5}{|c|}{ Heart function indices } \\
\hline $\mathrm{LDH}(\mathrm{U} / \mathrm{L})$ & $322(186-463)$ & $312(214.5-582)$ & 1.336 & 0.182 \\
\hline CK_MB $(\mathrm{ng} / \mathrm{ml})$ & $0.68(0.22-1.4)$ & $0.78(0.31-1.42)$ & 0.944 & 0.345 \\
\hline $\mathrm{CK}(\mathrm{U} / \mathrm{L})$ & 78(50-119) & $90(52-147)$ & -0.847 & 0.397 \\
\hline $\operatorname{TnI}(\mathrm{ng} / \mathrm{ml})$ & $0.01(0.01-0.01)$ & $0.01(0.01-0.01)$ & -2.118 & 0.034 \\
\hline \multicolumn{5}{|c|}{ Blood coagulation indices } \\
\hline $\operatorname{PLT}\left(10^{9} / \mathrm{L}\right)$ & $180(150-217)$ & 164(127-186) & -3.138 & 0.002 \\
\hline $\mathrm{PT}(\mathrm{s})$ & 12.05(11.4-12.5) & 12.2(11.55-12.75) & 1.965 & 0.049 \\
\hline APTT(s) & $34.95(32.15-38.2)$ & $36.8(34.35-41.3)$ & 2.312 & 0.021 \\
\hline D-DIC(ug/mL) & $0.34(0.24-0.47)$ & $0.5(0.31-0.96)$ & 3.961 & $<0.001$ \\
\hline \multicolumn{5}{|c|}{ Immune system function indices } \\
\hline $\mathrm{WBC}\left(10^{9} / \mathrm{L}\right)$ & $4.52(3.43-4.94)$ & 4.74(3.78-5.8) & 1.7 & 0.089 \\
\hline $\mathrm{N}\left(10^{9} / \mathrm{L}\right)$ & $2.29(1.72-3)$ & $2.99(2.27-4.38)$ & 3.928 & $<0.001$ \\
\hline $\mathrm{L}\left(10^{9} / \mathrm{L}\right)$ & $1.39(0.99-1.74)$ & $0.97(0.66-1.21)$ & -4.466 & $<0.001$ \\
\hline $\mathrm{PCT}(\mathrm{ng} / \mathrm{ml})$ & $0.00 .03-0.05)$ & $0.06(0.05-0.08)$ & -4.522 & $<0.001$ \\
\hline $\mathrm{CRP}(\mathrm{mg} / \mathrm{L})$ & $7.2(5-17.99)$ & 27(10.86-52.95) & 5.368 & $<0.001$ \\
\hline $\operatorname{ESR}(\mathrm{mm} / \mathrm{L})$ & $20(12-39)$ & $41.5(24.5-59.5)$ & -3.751 & $<0.001$ \\
\hline IL-6(ng/ml) & $12.13(4.43-17.02)$ & 23.6(16.63-37.01) & -4.81 & $<0.001$ \\
\hline \multicolumn{5}{|c|}{ Lung Function Index } \\
\hline Oxygenation index & 438(404-466) & $345(270-400)$ & 6.164 & $<0.001$ \\
\hline
\end{tabular}

\subsection{Inter-group comparison of categorical variables}

By converting quantitative variables to categorical variables, the ratio of abnormalities in each category was analyzed between the two groups. Statistically, the proportion of patients with abnormal level of each index were compared between the two groups. Higher $x^{2}$ value represents larger difference between the two groups. Based on the comparison, there were more male patients in the severe group which aligned with the result of previous research study.[6] There are higher proportions of patients with altered lymphocyte count, D-dimer level, albumin level, aspartate aminotransferase level, procalcitonin level, C- 
reactive protein level, erythrocyte sedimentation rate and interleukin-6 level in the severe group. More patients in the severe group have bilateral lung involvement and altered heart function in the severe group comparing to the mild group. Other indexes are not significantly different in statistical perspective. (Table 2, details in Table S1) This showed that COVID-19 infection have more extensive influence to organ function indices in the severe group.

Table 2: Comparison of the proportion of patients with abnormality in each categorical variable between the severe group and the mild group. Numbers in the bracket: percentages in the group;

$\mathrm{x}^{2}$ : Chi-Square test. 


\begin{tabular}{|c|c|c|c|c|}
\hline Categorical variables & $x^{2}$ & p-value & $\begin{array}{l}\text { Mild Group } \\
\text { No. of Patients } 1 \% \square\end{array}$ & $\begin{array}{c}\text { Severe Group } \\
\text { No. of Patients }(\%)\end{array}$ \\
\hline Gender & 5.858 & 0.016 & & \\
\hline Female & & & $43(58.9)$ & $24(38.1)$ \\
\hline Male & & & $30(41.1)$ & $39(61.9)$ \\
\hline Bilateral Lung Involvement & 7.337 & 0.007 & & \\
\hline No/Left lung/Right Lung & & & $13(24.07)$ & $3(5.56)$ \\
\hline Yes & & & $41(75.93)$ & $51(94.44)$ \\
\hline Coloured Echocardiography & 0.004 & 0.949 & & \\
\hline Normal/Near Normal & & & $7(100)$ & $17(89.47)$ \\
\hline Involved/Left atrial enlargement & & & $0(0)$ & $2(10.53)$ \\
\hline \multicolumn{5}{|c|}{ Liver function index level } \\
\hline $\mathrm{ALT}(\mathrm{U} / \mathrm{L})$ & 2.517 & 0.113 & & \\
\hline Within normal range & & & $7(9.59)$ & 12(19.05) \\
\hline Beyond normal range & & & $66(90.41)$ & $51(80.95)$ \\
\hline AST(U/L) & 9.453 & 0.002 & & \\
\hline Within normal range & & & $69(94.52)$ & $48(76.19)$ \\
\hline Beyond normal range & & & $4(5.48)$ & $15(23.81)$ \\
\hline TBIL(umol/L) & 0.893 & 0.345 & & \\
\hline Within normal range & & & $65(89.04)$ & $59(93.65)$ \\
\hline Beyond normal range & & & $8(10.96)$ & $4(6.35)$ \\
\hline $\mathrm{Alb}(\mathrm{g} / \mathrm{L})$ & 32.245 & $<0.001$ & & \\
\hline Within normal range & & & $67(91.78)$ & $30(47.62)$ \\
\hline Beyond normal range & & & $6(8.22)$ & $33(52.38)$ \\
\hline \multicolumn{5}{|c|}{ Kidney function index level } \\
\hline $\mathrm{Cr}$ (umol/L) & 0.137 & 0.711 & & \\
\hline Within normal range & & & $44(60.27)$ & $36(57.14)$ \\
\hline Beyond normal range & & & $29(39.73)$ & $27(42.86)$ \\
\hline \multicolumn{5}{|c|}{ Heart function index level } \\
\hline $\mathrm{LDH}(\mathrm{U} / \mathrm{L})$ & 0.104 & 0.747 & & \\
\hline Within normal range & & & $27(36.99)$ & $25(39.68)$ \\
\hline Beyond normal range & & & $46(63.01)$ & $38(60.32)$ \\
\hline CK_MB(ng/ml) & 0.568 & 0.451 & & \\
\hline Within normal range & & & $63(86.3)$ & $57(90.48)$ \\
\hline Beyond normal range & & & $10(13.7)$ & $6(9.52)$ \\
\hline CK(U/L) & 0.592 & 0.442 & & \\
\hline Within normal range & & & $21(28.77)$ & $22(34.92)$ \\
\hline Beyond normal range & & & $52(71.23)$ & $41(65.08)$ \\
\hline TnI(ng/ml) & 0.006 & 0.941 & & \\
\hline Within normal range & & & $73(100)$ & $62(98.41)$ \\
\hline Beyond normal range & & & $0(0)$ & $1(1.59)$ \\
\hline \multicolumn{5}{|c|}{ Blood coagulation index level } \\
\hline $\operatorname{PLT}\left(10^{9} / \mathrm{L}\right)$ & 3.453 & 0.063 & & \\
\hline Within normal range & & & 67(91.78) & $51(80.95)$ \\
\hline Beyond normal range & & & $6(8.22)$ & $12(19.05)$ \\
\hline $\mathrm{PT}(\mathrm{s})$ & 0.035 & 0.852 & & \\
\hline Within normal range & & & $60(82.19)$ & $51(80.95)$ \\
\hline Beyond normal range & & & $13(17.81)$ & $12(19.05)$ \\
\hline APTT(s) & 2.242 & 0.134 & & \\
\hline Within normal range & & & $61(83.56)$ & $46(73.02)$ \\
\hline Beyond normal range & & & $12(16.44)$ & $17(26.98)$ \\
\hline D-DIC(ug/mL) & 10.22 & 0.001 & & \\
\hline Within normal range & & & $60(82.19)$ & $36(57.14)$ \\
\hline Beyond normal range & & & $13(17.81)$ & $27(42.86)$ \\
\hline
\end{tabular}


Immune system function index level

\begin{tabular}{|c|c|c|c|c|}
\hline $\mathrm{WBC}\left(10^{9} / \mathrm{L}\right)$ & 0.377 & 0.539 & & \\
\hline Within normal range & & & $51(69.86)$ & $47(74.6)$ \\
\hline Beyond normal range & & & $22(30.14)$ & $16(25.4)$ \\
\hline $\mathrm{N}\left(10^{9} / \mathrm{L}\right)$ & 2.054 & 0.152 & & \\
\hline Within normal range & & & $50(68.49)$ & $50(79.37)$ \\
\hline Beyond normal range & & & $23(31.51)$ & $13(20.63)$ \\
\hline $\mathrm{L}\left(10^{9} / \mathrm{L}\right)$ & 9.837 & 0.002 & & \\
\hline Within normal range & & & $44(60.27)$ & $21(33.33)$ \\
\hline Beyond normal range & & & $29(39.73)$ & $42(66.67)$ \\
\hline PCT(ng/ml) & 8.476 & 0.004 & & \\
\hline Within normal range & & & $71(97.26)$ & $52(82.54)$ \\
\hline Beyond normal range & & & $2(2.74)$ & $11(17.46)$ \\
\hline $\mathrm{CRP}(\mathrm{mg} / \mathrm{L})$ & 17.831 & $<0.001$ & & \\
\hline Within normal range & & & $41(56.16)$ & $13(20.63)$ \\
\hline Beyond normal range & & & $32(43.84)$ & $50(79.37)$ \\
\hline $\mathrm{ESR}(\mathrm{mm} / \mathrm{L})$ & 15.299 & $<0.001$ & & \\
\hline Within normal range & & & $50(68.49)$ & $22(34.92)$ \\
\hline Beyond normal range & & & $23(31.51)$ & $41(65.08)$ \\
\hline IL-6(ng/ml) & 11.184 & 0.001 & & \\
\hline Within normal range & & & $52(71.23)$ & $27(42.86)$ \\
\hline Beyond normal range & & & $21(28.77)$ & $36(57.14)$ \\
\hline
\end{tabular}

\subsection{Effects of underlying diseases on the blood indices}

There are more patients with underlying diseases in the severe group comparing to the mild group. Thus, further analysis according to these underlying diseases was done to examine the effects of these underlying diseases on the variation of blood indices between the two groups. By comparing between the blood index levels quantitatively and qualitatively between patients with underlying diseases in the two groups, it was found that Cr, PCT, CRP, N, ESR, IL_6, PT, D_DIC were significantly higher in the severe group while levels of PLT and ALB were significantly higher in the mild group.(Table 3) This showed that underlying disease is indeed a factor affecting the severity of COVID-19 infection. Blood index levels were then compared respectively according to hypertension and diabetes which are most common underlying diseases observed from the patients. Elevated levels of PCT, CRP, N and decreased levels of PLT and ALB were observed from patients with diabetes in the severe group, where level of $\mathrm{N}$ increased both quantitatively and as a categorical variable. (Table 3) For those patients with hypertension in the severe group, levels of Cr, PCT, CRP, and ESR were significantly increased while levels of PLT and ALB were decreased, where levels of CRP, ESR and ALB were varied both quantitatively and as a categorical variable. (Table 3) Such results specifically highlighted the possibility of the influence of underlying diseases on the organ functions in the COVID-19 patients.

Table 3. Comparison of the levels of indices and the proportion with abnormality in each categorical variable between the patients with underlying diseases in the severe group and the mild group. 
Blood index levels in the patients with underlying diseases

Comparison of index levels

\begin{tabular}{|c|c|c|c|c|}
\hline & $\begin{array}{l}\text { Mean/Median Mild } \\
\text { Group }\end{array}$ & $\begin{array}{l}\text { Mean/Median Severe } \\
\text { Group }\end{array}$ & t or Z values & P-value \\
\hline Cr(umol/L) & $57.5(51-70)$ & $73.5(60-102)$ & $<0.001$ & 0.02 \\
\hline $\mathrm{PCT}(\mathrm{ng} / \mathrm{ml})$ & $0.03(0.02-0.05)$ & $0.07(0.05-0.12)$ & $<0.001$ & $<0.001$ \\
\hline $\mathrm{CRP}(\mathrm{mg} / \mathrm{L})$ & $5(5-13.25)$ & $30.6(20.2-53.98)$ & $<0.001$ & $<0.001$ \\
\hline $\mathrm{N}\left(10^{9} / \mathrm{L}\right)$ & $2.3(1.72-2.74)$ & $2.94(2.26-4.4)$ & $<0.001$ & 0.017 \\
\hline $\operatorname{ESR}(\mathrm{mm} / \mathrm{L})$ & $20(15-40)$ & $39.5(27-52)$ & $<0.001$ & 0.011 \\
\hline IL_6(ng/ml) & $9.89 \pm 7.04$ & $31.58 \pm 19.41$ & 0.000 & 0.001 \\
\hline $\operatorname{PLT}\left(10^{9} / \mathrm{L}\right)$ & 168(152-197) & 141(121-166) & 1.975 & 0.048 \\
\hline $\mathrm{PT}(\mathrm{s})$ & $11.75 \pm 0.99$ & $12.43 \pm 0.97$ & 0 & 0.042 \\
\hline D_DIC(ug/mL) & $0.4(0.27-0.5)$ & $0.52(0.36-1.1)$ & $<0.001$ & 0.033 \\
\hline $\operatorname{ALB}(g / L)$ & $43(41-46)$ & $39.35(36.8-41.4)$ & 3.451 & $<0.001$ \\
\hline \multicolumn{5}{|c|}{ Categorical variable of patients with underlying diseases } \\
\hline & $\chi^{2}$ & P-value & $\begin{array}{c}\text { Mild Group } \\
\text { No. of Patients } \\
\square \% \square \\
\end{array}$ & $\begin{array}{c}\text { Severe Group } \\
\text { No. of Patients } \\
\square \% \square \\
\end{array}$ \\
\hline $\mathrm{Cr}$ (umol/L) & 3.393366814 & 0.065459158 & & \\
\hline Within normal range & & & $10(38.46)$ & $16(61.54)$ \\
\hline $\begin{array}{l}\text { Beyond normal } \\
\text { range }\end{array}$ & & & $3(14.29)$ & $18(85.71)$ \\
\hline $\mathrm{PCT}(\mathrm{ng} / \mathrm{ml})$ & 2.718145524 & 0.099213223 & & \\
\hline Within normal range & & & $13(34.21)$ & $25(65.79)$ \\
\hline $\begin{array}{l}\text { Beyond normal } \\
\text { range }\end{array}$ & & & $0(0)$ & $9(100)$ \\
\hline $\mathrm{CRP}(\mathrm{mg} / \mathrm{L})$ & 10.88810087 & 0.00096784 & & \\
\hline Within normal range & & & $9(64.29)$ & $5(35.71)$ \\
\hline $\begin{array}{l}\text { Beyond normal } \\
\text { range }\end{array}$ & & & $4(12.12)$ & $29(87.88)$ \\
\hline $\mathrm{N}\left(10^{9} / \mathrm{L}\right)$ & 0.43454142 & 0.509768915 & & \\
\hline Within normal range & & & $8(23.53)$ & $26(76.47)$ \\
\hline $\begin{array}{l}\text { Beyond normal } \\
\text { range }\end{array}$ & & & $5(38.46)$ & $8(61.54)$ \\
\hline $\operatorname{ESR}(\mathrm{mm} / \mathrm{L})$ & 8.684012066 & 0.003210135 & & \\
\hline Within normal range & & & $10(50)$ & $10(50)$ \\
\hline $\begin{array}{c}\text { Beyond normal } \\
\text { range }\end{array}$ & & & $3(11.11)$ & $24(88.89)$ \\
\hline IL_6(ng/ml) & 0.103126463 & 0.748109534 & & \\
\hline Within normal range & & & $9(31.03)$ & $20(68.97)$ \\
\hline $\begin{array}{l}\text { Beyond normal } \\
\text { range }\end{array}$ & & & $4(22.22)$ & $14(77.78)$ \\
\hline $\operatorname{PLT}\left(10^{9} / \mathrm{L}\right)$ & 1.01743763 & 0.313127583 & & \\
\hline Within normal range & & & $12(32.43)$ & $25(67.57)$ \\
\hline $\begin{array}{c}\text { Beyond normal } \\
\text { range }\end{array}$ & & & $1(10)$ & $9(90)$ \\
\hline $\mathrm{PT}(\mathrm{s})$ & 0.124124446 & 0.724603544 & & \\
\hline Within normal range & & & $9(25)$ & $27(75)$ \\
\hline $\begin{array}{l}\text { Beyond normal } \\
\text { range }\end{array}$ & & & $4(36.36)$ & $7(63.64)$ \\
\hline D_DIC(ug/mL) & 2.788532764 & 0.09494112 & & \\
\hline
\end{tabular}




\begin{tabular}{c|c|c|c|c}
\hline $\begin{array}{c}\text { Within normal range } \\
\text { Beyond normal } \\
\text { range }\end{array}$ & & & $10(37.04)$ & $17(62.96)$ \\
\cline { 2 - 5 } & & & $3(15)$ & $17(85)$ \\
\hline ALB(g/L) & 13.52783379 & 0.000235051 & & $11(47.83)$ \\
\cline { 2 - 5 } $\begin{array}{c}\text { Within normal range } \\
\text { Beyond normal } \\
\text { range }\end{array}$ & & & $12(52.17)$ & $23(95.83)$ \\
\hline
\end{tabular}

Blood index levels in the patients with diabetes

Comparison of index levels

\begin{tabular}{c|c|c|c|c}
\hline & $\begin{array}{c}\text { Mean/Median Mild } \\
\text { Group }\end{array}$ & $\begin{array}{c}\text { Mean/Median Severe } \\
\text { Group }\end{array}$ & t or Z values & P-value \\
\hline PCT(ng/ml) & $0.03(0.02-0.03)$ & $0.07(0.06-0.12)$ & $<0.001$ & 0.011 \\
\hline CRP(mg/L) & $12.35(5-24.05)$ & $31.95(22-55.3)$ & $<0.001$ & 0.043 \\
\hline $\mathbf{N}\left(10^{9} / \mathrm{L}\right)$ & $1.65(1.22-2.36)$ & $2.34(2.2-3.16)$ & $<0.001$ & 0.079 \\
\cline { 2 - 5 } PLT(10 $/ \mathrm{L})$ & $173.25 \pm 26.65$ & $136.58 \pm 27.39$ & 2.332 & 0.035 \\
\hline ALB(g/L) & $43.5 \pm 4.95$ & $38.88 \pm 4.3$ & 1.797 & 0.094 \\
\hline
\end{tabular}

Categorical variable of patients with diabetes

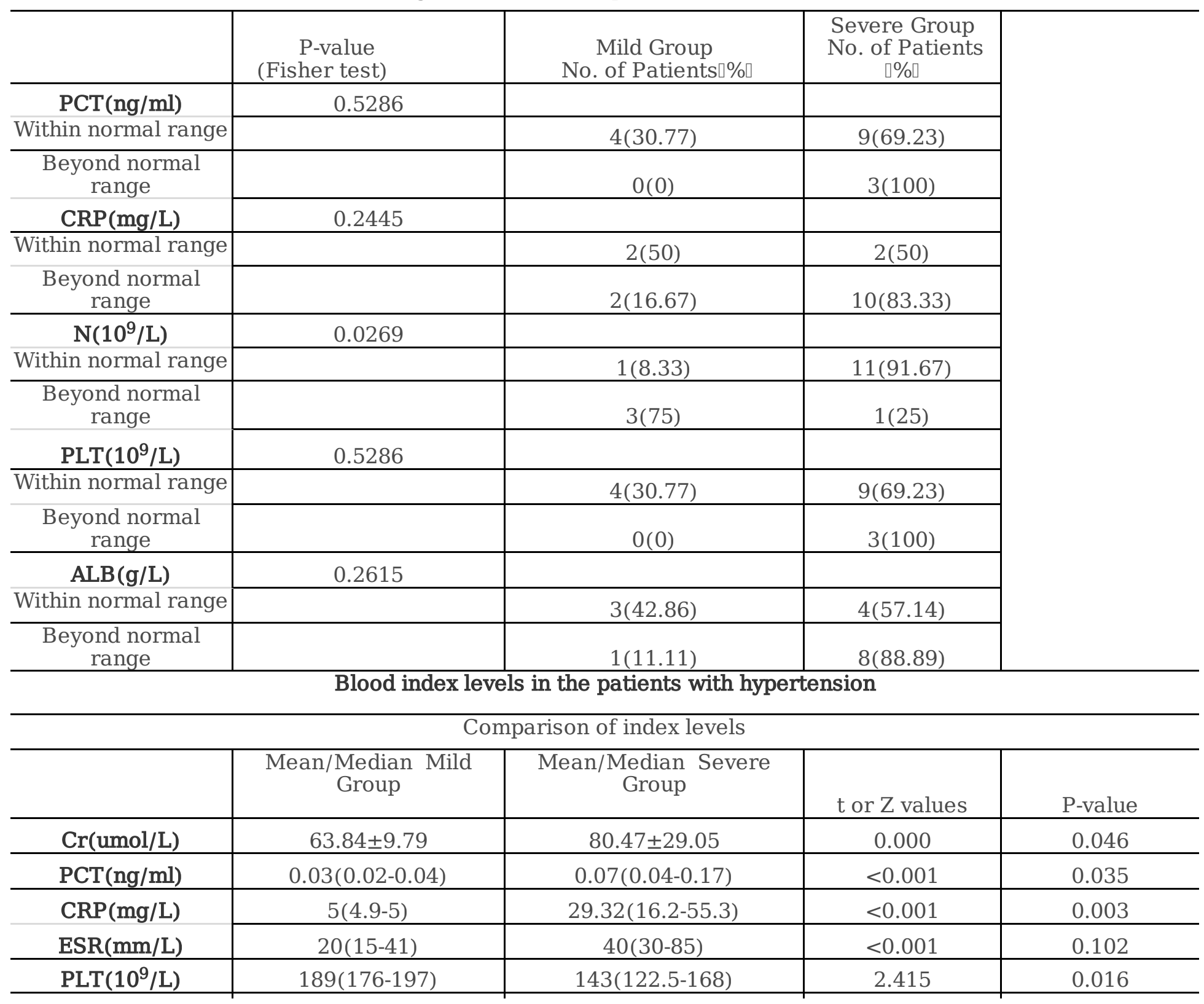

Page $11 / 15$ 


\begin{tabular}{|c|c|c|c|}
\hline $\operatorname{ALB}(g / L)$ & $44.66 \pm 2.76$ & $38.54 \pm 4.11$ & 3.137 \\
\hline \multicolumn{4}{|c|}{ Categorical variable of patients with diabetes } \\
\hline & $\begin{array}{c}\text { P-value } \\
\text { (Fisher test) }\end{array}$ & $\begin{array}{c}\text { Mild Group } \\
\text { No. of Patients } \square \square\end{array}$ & $\begin{array}{c}\text { Severe Group } \\
\text { No. of Patients } \\
\square \% \square \\
\end{array}$ \\
\hline Cr(umol/L) & 0.3406 & & \\
\hline Within normal range & & $4(28.57)$ & $10(71.43)$ \\
\hline $\begin{array}{c}\text { Beyond normal } \\
\text { range }\end{array}$ & & $1(9.09)$ & $10(90.91)$ \\
\hline $\mathrm{PCT}(\mathrm{ng} / \mathrm{ml})$ & 0.2743 & & \\
\hline Within normal range & & $5(27.78)$ & 13(72.22) \\
\hline $\begin{array}{c}\text { Beyond normal } \\
\text { range }\end{array}$ & & $0(0)$ & $7(100)$ \\
\hline $\mathrm{CRP}(\mathrm{mg} / \mathrm{L})$ & 0.0123 & & \\
\hline Within normal range & & $4(57.14)$ & $3(42.86)$ \\
\hline $\begin{array}{c}\text { Beyond normal } \\
\text { range }\end{array}$ & & $1(5.56)$ & $17(94.44)$ \\
\hline \multirow{2}{*}{$\begin{array}{c}\text { ESR(mm/L) } \\
\text { Within normal range }\end{array}$} & 0.0377 & & \\
\hline & & $3(60)$ & $2(40)$ \\
\hline $\begin{array}{c}\text { Beyond normal } \\
\text { range }\end{array}$ & & $2(10)$ & 18(90) \\
\hline $\operatorname{PLT}\left(10^{9} / \mathrm{L}\right)$ & 0.544 & & \\
\hline Within normal range & & $5(25)$ & $15(75)$ \\
\hline $\begin{array}{c}\text { Beyond normal } \\
\text { range }\end{array}$ & & $0(0)$ & $5(100)$ \\
\hline$A L B(g / L)$ & 0.0149 & & \\
\hline Within normal range & & $5(41.67)$ & $7(58.33)$ \\
\hline $\begin{array}{c}\text { Beyond normal } \\
\text { range }\end{array}$ & & $0(0)$ & $13(100)$ \\
\hline
\end{tabular}

\section{Discussion}

Here we analysed the differences between the levels of organ functional indices detected from peripheral venous blood samples between two cohorts of patients with either severe or mild COVID-19 pneumonia infection. We measured the biochemical indexes and blood routine indexes in the early stage of medication in order to avoid damage the functions of patients' major organs including liver, kidney and other organs in the course of medication. Through inter-group comparison, it was found that levels of ALT, AST and $\mathrm{Cr}$ were significantly higher in the severe group $(\mathrm{p}<0.05)$, reflecting a higher vulnerability of severe patients to the damage of liver and kidney functions. Our results also indicated from the perspective of blood index levels the influence of underlying diseases on the organ functions in the severe group.

It has been reported that human coronavirus is able to replicate quickly after infection while causes extensive infiltration of inflammatory cells and enhanced responses of pro-inflammatory cytokine/chemokine.[13]Another group has also described the pathophysiological changes of COVID-19 infection using "cytokine storm". This series of changes would lead to systemic inflammatory response syndrome and induce related organ damage in the patients. In the early stage of infection, some patients 
had respiratory distress syndrome and decreased lung ventilation ability which lead to hypoxia of organs and tissues. Hypoxia would result in oxidative stress responses of the body while the continuous increase of reactive oxygen species and its peroxides could further promote the release of proinflammatory factors, aggravating liver and kidney function damages.[14] Angiotensin-converting enzyme 2 (ACE-2) receptors are distributed over the cells surface of brain, heart, kidney, liver, lungs and etc. Being a linear single positive strand RNA virus, COVID-19 virus infects human cells by interacting with ACE-2 receptors through RBS domains of $S$ proteins inducing a series of pathological changes and related organ function damages.[15] Our results also confirmed that patients in the severe group had significantly altered level of inflammatory indices including lymphocyte count, PCT, CRP, ESR, IL- 6 and etc, and higher proportion of bilateral lung involvement, comparing to those in the mild group. This also indicates that severe patients are more prone to have inflammatory storm and hypoxia of respiratory distress tissue.

Moreover, patients in the severe group have higher average age and more chronic diseases which make them more vulnerable to liver and kidney function damages under the influence of inflammatory storm comparing to the patients in the mild group. There are several studies reported on the organ damage in the COVID-19 patients. Cui et.al has reported a case of female infant with COVID-19 pneumonia presented damages on liver and heart, diagnosed by laboratory examinations.[16] Liver dysfunctions as indicated mostly by increased AST levels in the COVID-19 patients were also reported. The mechanisms of the induction of these liver dysfunctions were postulated due to mediation of ACE2, inflammatory responses, hypoxia and even medications.[17] Our group has also reported one severe patient with onset of viral hepatitis after confirmed with COVID-19 infection.[18] Kidney damages related to COVID-19 were possibly induced in the patients by cytokine storm, organ crosstalk and Systemic effects.[19] This disease is also more severe in the immunocompromised kidney transplant recipient. [20] COVID-19related myocardiac injury was due to SARS-CoV-2 invasion mediated by ACE-2. [21] One case in the severe group had definite myocardial injury which is resulted from viral myocarditis caused by COVID-19 virus. There is no difference statistically in the levels of CK-MB and Tnl in other severe patients comparing to those in the mild group ( $P>0.05)$. Further dynamic observation and analysis are still needed due to the factors of sample size and collection time of peripheral blood. In summary, patients with severe COVID-19 pneumonia infection are possibly associated with different organ damages in the early stage, such as in the lung, the liver, the kidney and etc. Therefore, it is necessary to dynamically monitor the relevant organ function indices for prompt drug intervention, prevention of aggravation of patients' conditions and improvement of prognosis.

\section{Declarations}

\section{Conflict of interest}

The authors declare that they have no conflict of interests.

\section{Funding}


This work is supported by Natural Science Foundation of China (81672003) and National Science and Technology Major Project(2017ZX10103011).

\section{Previous presentation}

The information in this study has not been presented in any meeting previously.

\section{Correspondence}

Liang Yang (yangl@sustech.edu.cn) and Fuxiang Wang (wangfuxiang999@163.com) contributed equally as corresponding authors.

\section{Ethics Statement}

This study is approved by the Ethics Committees from Shenzhen Third People's Hospital(2020-142). The need for consent was waived by the approving ethics committee.

\section{References}

1. Li Q, Guan X, Wu P, et al. Early Transmission Dynamics in Wuhan, China, of Novel CoronavirusInfected Pneumonia. N Engl J Med 2020; 382:1199-207.

2. Lan J, Ge J, Yu J, et al. Structure of the SARS-CoV-2 spike receptor-binding domain bound to the ACE2 receptor. Nature 2020; 581:215-20.

3. Xia J, Tong J, Liu M, Shen Y, Guo D. Evaluation of coronavirus in tears and conjunctival secretions of patients with SARS-CoV-2 infection. J Med Virol 2020.

4. Zhou F, Yu T, Du R, et al. Clinical course and risk factors for mortality of adult inpatients with COVID19 in Wuhan, China: a retrospective cohort study. Lancet 2020; 395:1054-62.

5. Liu K, Chen Y, Lin R, Han K. Clinical features of COVID-19 in elderly patients: A comparison with young and middle-aged patients. J Infect 2020.

6. Chen N, Zhou M, Dong X, et al. Epidemiological and clinical characteristics of 99 cases of 2019 novel coronavirus pneumonia in Wuhan, China: a descriptive study. Lancet 2020; 395:507-13.

7. Ruan Q, Yang K, Wang W, Jiang L, Song J. Clinical predictors of mortality due to COVID-19 based on an analysis of data of 150 patients from Wuhan, China. Intensive care medicine 2020.

8. Shen C, Wang Z, Zhao F, et al. Treatment of 5 Critically III Patients With COVID-19 With Convalescent Plasma. JAMA 2020.

9. Wan S, Xiang Y, Fang W, et al. Clinical features and treatment of COVID-19 patients in northeast Chongqing. J Med Virol 2020.

10. Wang T, Du Z, Zhu F, et al. Comorbidities and multi-organ injuries in the treatment of COVID-19. Lancet 2020; 395:e52. 
11. Wang D, Hu B, Hu C, et al. Clinical Characteristics of 138 Hospitalized Patients With 2019 Novel Coronavirus-Infected Pneumonia in Wuhan, China. JAMA 2020.

12. Gandolfini I, Delsante M, Fiaccadori E, et al. COVID-19 in Kidney Transplant Recipients. Am J Transplant 2020.

13. Channappanavar R, Perlman S. Pathogenic human coronavirus infections: causes and consequences of cytokine storm and immunopathology. Seminars in immunopathology 2017; 39:529-39.

14. Zi-xue XG-b, ZHANG ; Xiao-lan, YE; Ping, HUANG Cause analysis of liver injury in patients infected by novel coronavirus and suggestion of drug monitoring[J]. Chinese Pharmacological Bulletin 2020; 02:1-2.

15. Xu X, Chen P, Wang J, et al. Evolution of the novel coronavirus from the ongoing Wuhan outbreak and modeling of its spike protein for risk of human transmission. Sci China Life Sci 2020; 63:457-60.

16. Cui Y, Tian M, Huang D, et al. A 55-Day-Old Female Infant Infected With 2019 Novel Coronavirus Disease: Presenting With Pneumonia, Liver Injury, and Heart Damage. J Infect Dis 2020; 221:177581.

17. Feng G, Zheng KI, Yan QQ, et al. COVID-19 and Liver Dysfunction: Current Insights and Emergent Therapeutic Strategies. J Clin Transl Hepatol 2020; 8:18-24.

18. Zhang P, Cai Z, Wu W, et al. The novel coronavirus (COVID-19) pneumonia with negative detection of viral ribonucleic acid from nasopharyngeal swabs: a case report. BMC Infect Dis 2020; 20:317.

19. Ronco C, Reis T. Kidney involvement in COVID-19 and rationale for extracorporeal therapies. Nat Rev Nephrol 2020; 16:308-10.

20. Zhu L, Gong N, Liu B, et al. Coronavirus Disease 2019 Pneumonia in Immunosuppressed Renal Transplant Recipients: A Summary of 10 Confirmed Cases in Wuhan, China. Eur Urol 2020.

21. Guzik TJ, Mohiddin SA, Dimarco A, et al. COVID-19 and the cardiovascular system: implications for risk assessment, diagnosis, and treatment options. Cardiovasc Res 2020.

\section{Supplementary Files}

This is a list of supplementary files associated with this preprint. Click to download.

- ShiyanFengOrgandamageindicatorsofCOVID19TableS1.xIsx 